\title{
An Exploratory Perspective of Student Performance and Access to Resources
}

\author{
Elmarie Papageorgiou
}

\author{
School of Accountancy, University of the Witwatersrand, Johannesburg
}

\section{Chris William Callaghan}

School of Economic and Business Sciences, University of the Witwatersrand, Johannesburg

Email: chris.callaghan@wits.ac.za

Doi:10.5901/mjss.2014.v5n23p2234

\begin{abstract}
This research investigated the relationships between potential constraints to students' access to technological resources and student academic performance. Longitudinal data from 2010 ( $n=228), 2011(n=340)$ and 2012 ( $n=347)$ from South African accounting students was used to test the relationships between technological resources access and student academic performance using correlation analysis, multiple linear regression analysis and factor analysis. Access to the latest software was found to be associated with student academic performance; a 'digital divide' between students may influence their academic performance. This research specifically identifies certain constraints potentially associated with a 'digital divide' that may influence student performance.
\end{abstract}

Keywords: Accounting education; gender inequality; South Africa; technology; digital divide.

\section{Introduction}

South Africa is one of the most unequal societies in the world (Özler, 2007). With a GINI coefficient (a measure of statistical dispersion of income) of .56 in 1995 (Özler, 2007) and of 63.1 in 2009 (The World Bank 2012), inequality might be increasing. This resource inequality is mirrored in a deepening digital divide; reflected in the emergence of a 'digital elite'; of individuals that have been exposed to technology and are fluent in its use versus those that have not (Brown \& Czerniewicz, 2010). One's life chances in South Africa typically relate to which side of this digital divide an individual is on (Brown \& Czerniewicz, 2010).

This inequality, however, is also reflected in current ratings of the South African education system. According to the World Economic Forum survey, South Africa currently has the fifth-lowest rated education system in the world (World Economic Forum, 2012). In contrast, the country also has the fifteenth-highest rated management/business schools in the world (World Economic Forum 2012).

Currently, South Africa's higher education context is under increasing pressure to transform itself in order to address cultural, economic and gender exclusion (Van Wyk \& Jacobs, 2012). Knowledge is of increasing importance in a knowledge-driven economy; economic development is a function of knowledge creation (Van Wyk \& Jacobs, 2012). Higher education creates knowledge that also contributes to economic development though its enablement of entrepreneurship (Olele \& Uche, 2012). Education is therefore taken to be a primary driver of change in this context.

South Africa's human capital base for entrepreneurship, and therefore job creation, is relatively low based on international measures (Urban, Van Vuuren \& Barreira, 2008). Operationalising entrepreneurship education (Isaacs, Visser, Friedrich \& Brijlal, 2007:262) through the provision of business-related education, such as accounting education by tertiary education institutions, plays an important role in societal economic development.

This paper investigates the potential influence of inequality in access to technological resources on accounting student performance in a large South African university. In the absence of other literature that does so, this study attempts to provide an investigation of the specific dimensions of lack of student access to technological resources and their relationships with student performance.

Firstly, in order to understand the influence of unequal access to technological resources in the university context of accounting, it is necessary to also understand the influence of unequal access to resources at the school level. Access to resources within the schooling system in South Africa is not equal (O'Connor \& Geiger, 2009:266). Support and resources differ between schools and certain schools in disadvantaged areas typically experience considerably higher 
workloads, overcrowded classrooms and other forms of resource scarcity (O'Connor \& Geiger, 2009:266).

Learners also need to negotiate an educational landscape that is largely dominated by English-language teaching (O'Connor \& Geiger, 2009:266). Academic and socio-emotional experiences are, therefore, typically unequal (O'Connor \& Geiger, 2009:266). If technological literacy can be likened to competence in a language (Prensky, 2001) then it may represent yet another language that a student needs to learn. It is argued that a lack of knowledge of these constraints imposes a cost; to the individual student, to the university, and to society itself.

In order to transcend the digital divide (Brown \& Czerniewicz, 2010); differences of technological literacy between those that are technologically literate and those that are not, that differentiates work and life opportunities in the South African context, it is important to know specifically what the potential technology-related constraints to student academic performance are. This study seeks to contribute to the education literature by identifying certain of these constraints in a context of change; over a three year period, in order to offer a perspective of change over time in this context. It is argued that educational research in the South African context offers important insights into how education can contribute to societal change, given that this context is dynamic and might offer vantage points and insights less accessible to researchers in developed contexts.

\section{Research Problem}

Despite a wide range of literature that relates to student performance, absent from the literature is knowledge of the specific influence of unequal access to the technological requirements of accounting studies in the South African context. More specifically, the relationships between accounting student performance and technological literacy, access to personal technological resources, and gender seems as yet to be under-researched in this context. This study addresses this problem, and the research question addressed in this research is therefore: What is the relationship between access to technology and accounting student performance?

It is argued that knowledge of these relationships is particularly important in the South African context of higher education; and particularly so because of the societal change the country is experiencing. Further knowledge of these relationships may also provide insight into resource scarce contexts in general. As already indicated, knowledge of these relationships may offer educational practitioners an opportunity to address constraints to student performance if they know specifically what these constraints are. Having given an overview of the research problem, the theoretical framework of the paper is now introduced, and hypotheses are derived.

\section{Theoretical Framework and Hypotheses}

The study is now placed in relation to the body of accounting education technology research, and the broader theoretical frameworks that are specific to this body of literature.

Historically, within the field of accounting education, different types of educational technology research have emerged, typically derived from two theoretical origins; behaviourism and cognitivism (Bryant \& Hunton, 2000).

Behaviourism theory is premised on the notion that the manipulation of variables within the control of the educator can achieve a "desired, quantifiable outcome" (Bryant \& Hunton, 2000:136). According to this body of theory, stimulus is provided to students in the form of new material and reinforcement (which may be positive or negative) and this is used to improve learning (Bryant \& Hunton, 2000). A flaw inherent in behaviourism is its neglect of the influence of individual attributes (Bryant \& Hunton, 2000).

Cognitivism, therefore, has become the "theory of choice" in this field because of its focus on the identification of "learner variables that mediate learning" and the mental processes that influence individual learning, according to Bryant \& Hunton (2000:137).

However, approaches to technological education should therefore incorporate both bodies of theory in their research, to take advantage of synergies (Bryant \& Hunton, 2000). This research falls into the category of evaluation research. Evaluation research is concerned with the influence of different aspects of teaching on student learning (Bryant \& Hunton, 2000). In this paper, the 'net' effect of differences in access to technology is tested as to its potential influence on student learning, measured as student marks in a first year accountancy course.

Although examples of educational interventions to develop critical responsiveness amongst students "about the discourse of human rights, democracy and social responsibility" exist, and are ongoing in the South African context (Nanackchand \& Berman, 2012:477), it is argued that developing such understandings may need to be underpinned by lecturing interventions that continue to seek out and address existing constraints to inequality in university learning contexts; otherwise continuing inequality may ultimately threaten the very project of democracy (Munusamy, 2012), 
associated as it is with human rights and social responsibility.

Similarly, individual and group pathologies cannot explain poverty and unemployment when the "structural barriers that create and maintain problems" are not first addressed (Ginwright \& Cammarota, 2002:82). The reconceptualisation of youth development; toward the 'positive' youth development model, has been associated with a focus on the acknowledgement of the self-worth and empowerment of young people (Ginwright \& Cammarota, 2002:84). Notwithstanding the wealth of research that has developed according to the positive youth development model, which is associated with building on the positive aspects of youth development, oppressive community conditions are still dominant, and debilitating constraints to youth development remain (Ginwright \& Cammarota, 2002:84). Resource constraints, therefore, can be a barrier that constrains one's life chances. Furthermore, the barriers to access to resources can have their antecedents in complex contextual circumstances that shape life experiences (Ginwright \& Cammarota, 2002:85).

Like "universities worldwide, South African higher education institutions are facing increasing massification, with both more students entering higher education (enrolments increased by 25\% between 1995 and 2007) and increased diversity (Brown \& Czerniewicz, 2010:358). Technology can improve student performance when applications support the curriculum standards that are being assessed (Cradler, McNabb, Freeman \& Burchet, 2002). Access to the Internet has been associated with the same (Cradler et al., 2002). Similarly, exposure to technology may also enable cognitive development (Cradler et al., 2002). Where working contexts require the use of technology, the benefits of technology usage in learning contexts are particularly salient (Cradler et al., 2002).

The globalisation of business and education systems has, however, created a context that has privileged English as a dominant language (Phillipson, 1996). The need to develop fluency in yet another language; the language of technology, however, is necessary in order to be able to bridge the technological divide (Brown \& Czerniewicz, 2010).

Constraints to technological literacy are therefore expected to be reflected in demographic variables that capture the political inequality of the past. Societal gender inequality persists in the South African context and is reflected in high rates of gender-based violence (Dunkle, Jewkes, Brown, Yoshihama, Gray, McIntyre \& Harlow, 2004). Cultural forces impose different roles on females versus males (Ridgeway \& Correll, 2004). Gender differences therefore result from an "institutionalised system of social practices for constituting people as two significantly different categories" (Ridgeway \& Correll, 2004:510). As a consequence of this, social relations of inequality are organised "on the basis of that difference (Ridgeway \& Correll, 2004:510). Discrimination and gender disadvantages that accrue to females in work contexts are well documented (Morrison, White \& Van Velsor, 1987; Powell \& Butterfield, 2002; Xie \& Shauman, 2003). On the basis of the literature that relates to this gender inequality, Hypothesis (a) is offered; that student academic performance is significantly associated with gender. The provision of quality educational facilities such as computer laboratories is expected to contribute to environments that are conducive to quality education (Xaba, 2012:216). Barriers to access to resources that are the result of social inequality (Ginwright \& Cammarota, 2002) can be expected to manifest in unequal levels of technological literacy. Constraints to access to technological resources might be expected to constrain knowledge of Excel, Word and Access, or technological literacy, which may in turn be reflected in unequal student performance.

Similarly, the extent to which a student uses the twenty-four hour laboratory services might also indicate that they do not have access to resources at home, or in residences. A student with no alternative to the use of university computer laboratories might be more vulnerable to equipment scarcity in peak periods in the laboratories. The same constraint to equipment scarcity might be present at home, or at the university residences, as a student might have to share a computer at home with others. These are all considered to be dimensions of technological resources constraints that may constrain student performance. Variables are therefore included that relate to these dimensions of technology constraint. Hypothesis (b) is therefore offered, that access to technological resources is significantly associated with student performance. Unequal access to resources within the schooling system (O'Connor \& Geiger, 2009:266), and economic resource-inequalities that are the result of the historical context of the country (Özler, 2007) may influence student performance. Access to technological resources might be particularly salient in a global context where technology can enable radical changes in innovation (Callaghan, 2014a), even when research productivity in universities may be constrained by values (Callaghan, 2014b). Irrespective of the impact of different interests and aptitudes of students (Coldwell \& Callaghan, 2013), unequal access to technology may constrain student performance despite other enabling factors.

If resource scarcity is a dominant constraint to the development of youth (Ginwright \& Cammarota, 2002:84), and if resource constraints are reflected in the source of payments students use to pay for studies, then constraints to access to resources, proxied by payment source for studies, is expected to be reflected in tested relationships with student performance. Age, the need for a student to engage with part-time work, gender, ethnicity, ownership of a computer, and 
type of operating system software are all taken to be dimensions associated with access to resources in general. In order to understand the interplay of technological and resources factors in this context, it is also important to understand the factor structure of these.

The study of the influence of a student's access to technological resources in their studies and access to other resources on their academic performance is important in the current context for a number of reasons. Prensky (2001) differentiates between the new generation of students that are fluent in technology and who have grown up in a technological world, and the teachers that have grown up in a different, pre-technological age, who are struggling to teach this generation. For these students, according to Prensky (2001), different levels of exposure to technology may have led to physical differences in brain structure and in radically different ways of processing knowledge. For Prensky (2001:1) this has resulted in a fundamental societal differentiation, because individuals that grow up in a technologically dominated world "think and process information fundamentally differently from their predecessors". Prensky (2001:2) argues that technology is akin to a language, and "a language learned later in life, scientists tell us, goes into a different part of the brain".

In the South African student context, students do not typically engage with Web 2.0 based technologies and do not seem to "be interested in using them in their studies" (Thinyane, 2010). The extent to which individuals are excluded from technology might fundamentally influence their life chances in a technological world. Brown and Czerniewicz (2010) stress that this differentiation exists as a form of digital divide, and whereas research undertaken by Prensky (2001) relates to developed-world contexts, in the South African context individuals exposed to technology over their entire lifetimes are instead part of a digital 'elite'. For Brown and Czerniewicz (2010:357):

Instead of a new net generation growing up to replace an older analogue generation, there is a deepening digital divide in South African characterised not by age but by access and opportunity; indeed, digital apartheid is alive and well.

This study therefore seeks to test the potential influence of constraints to access to technology on student academic performance. Knowledge of these constraints is considered to be particularly important in the South African societal context which is dominated by resources inequality (Brown \& Czerniewicz, 2010:357). The methodology of the study is now introduced.

\section{Research Methodology}

The study used an exploratory longitudinal associative research design. Three samples were drawn from a first year accounting class across the years $2010(n=228), 2011(n=341)$ and 2012( $n=344)$. The enrolments for the class were 278(2010), 376(2011) and 383(2012), giving a response rate of 82\% (2010), 91\%, (2011) and 89.8\% (2012), respectively. The Data were collected electronically and analysed using SPSS statistical software. Univariate and multivariate techniques were used to analyse the data. Table 1 reports the respondent demographics. Females are the majority in all the three years.

Two by two, between subjects factorial ANOVA was used in order to test the differences in means of student marks by gender and their interactions. Multiple linear regression models were also used. Exploratory backward elimination was used to obtain equations for each of the years. Variables within these models with a significance level of $p<.05$ were then interpreted. Backward elimination was considered to be acceptable because the inclusion of all the tested variables was based on theory (Field, 2009).

A factor analysis of the structure of the data provided insight into underlying component categories in the data. Applying this analysis across the three years enabled a longitudinal perspective of potential changes in the underlying structure of factors over time. Scales were constructed based on previous precedent used in other studies. Scales were simplified. No psychographic items were required; the items were clear and unambiguous. The items were piloted prior to use. Reliability and validity were ensured. An orthogonal Varimax rotation was applied to the factor analysis. The factor structure was found to be relatively constant across the three years.

In order to provide a justification for what variables to include in the multiple linear regression analysis, tests were performed in order to identify the presence of multicollinearity. The factor analysis results also provided information that was used to avoid the presence of singularity and multicollinearity within the multiple linear regression models. One variable from each of the component categories of the factor analysis (the one with the highest loading) was included in the multiple linear regression analysis together with other biographical variables. The following variables were therefore included in the multiple linear regression analysis: knowledge of Excel; the use of printing facilities; extent of use of the twenty-four hour laboratory facilities; time spent waiting for computers; age; part-time work; and the number of other people that share a computer at home. These variables were taken to represent interval or ratio data. Also included in the multiple linear regression model were binary (dummy) variables relating to gender, race variables (used only for control 
purposes), source of payment of studies (parents, National Student Financial Aid Scheme (NSFAS) loan or bursary); ownership of own computer; and type of operating system (Windows XP, 7, 2000 and Vista). The results are now reported and discussed.

\section{Results and Discussion}

The results of the testing of the hypotheses are now reported and discussed as follows.

Hypothesis a: Student Performance is significantly associated with Gender.

\subsection{Data}

In the 2010 sample, 103 of the respondents were male and 126 female (Table 1).

Table 1: Respondent demographics

\begin{tabular}{|c|c|c|c|c|c|c|c|c|}
\hline & \multicolumn{2}{|l|}{2010} & \multicolumn{2}{|l|}{2011} & \multicolumn{2}{|l|}{2012} & \multicolumn{2}{|c|}{ Total } \\
\hline & Frequency & $\%$ & Frequency & $\%$ & Frequency & $\%$ & Frequency & $\%$ \\
\hline Registered for Acc I & 278 & 100 & 376 & 100 & 383 & 100 & 1037 & 100 \\
\hline Responses & 228 & 82 & 341 & 91 & 344 & 89.8 & 913 & 88.04 \\
\hline \multicolumn{9}{|l|}{ Gender } \\
\hline Male & 103 & 45 & 160 & 47 & 173 & 47 & 436 & 47 \\
\hline Female & 126 & 55 & 181 & 53 & 196 & 53 & 503 & 53 \\
\hline Total & 229 & 100 & 341 & 100 & 369 & 100 & 939 & 100 \\
\hline \multicolumn{9}{|l|}{ Own Computer } \\
\hline Own computer & 160 & 70 & 239 & 70 & 273 & 74 & 672 & 72 \\
\hline
\end{tabular}

The results of the ANOVA tests indicate that student marks are significantly different by gender ( $F=5.02$; $p<.026$;PartialEtaSquared=.022). The significant gender differences are surprising. As can be seen in Figure 1, female students are found to perform significantly better than male students. In contrast to other contexts which have been found to be gender-discriminatory (Morrison, White \& Van Velsor, 1987; Powell \& Butterfield, 2002; Xie \& Shauman, 2003), this context might be well-suited to female students. Marks are found to be significantly higher for white students $(F=4.218 ; p<.012 ;$ PartialEtaSquared=.028). Further research is recommended into why female students outperform male students in this context. Females are also the majority in the class (55\%). This was the only year, however, that female students were found to significantly outperform male students. Having established that inequality is present in this context, the testing of the other hypotheses is expected to provide insight into the specific role of constraints to technological access associated with this inequality. Certain males face restriction in their employment opportunities in South Africa, due to Affirmative Action and Employment Equity policies, which favour females in employment (Habib \& Bentley, 2008).

\subsection{Data}

The 2011 data included 160 males and 181 females. According to the ANOVA tests of the 2011 data no difference in marks was found by gender.

\subsection{Data}

Of the total respondents in 2012, 162 were male and 186 were female. Differences in student marks by gender were not found to be significant in this data. The multivariate results are reported and discussed as follows.

Hypothesis b: Access to technological resources is significantly associated with student performance.

Multiple linear regression analysis was used in order to provide a multivariate understanding of the associations between the tested factors and student performance. The influence of certain variables with the inclusion of covariates was expected to reveal the relationships of variables after the influence of other variables were controlled for within the models (Field, 2009). Race variables were controlled for in all the multiple regressions; as control variables, these variables are not included in the following discussion. Backward elimination was used. 


\subsection{Data}

For the 2010 data, two models were run with accounting marks as the dependent variable. The first model included all the tested factors. A backward elimination multiple linear regression analysis was run to obtain the second model. Bootstrapping was applied. The first model returned an R Squared value of .125 and an adjusted R Squared value of .041. The Durbin-Watson statistic for this model was 2.219 which indicated that serial correlation was not a serious problem for the model. However, the model was not significant $(p<.086)$. The model was taken to possibly include too many non-significant variables, which can render the entire model non-significant (Field, 2009). The model was not interpreted. The second model only included variables that were significant at within the ten percent level of significance. After seventeen iterations, the final model returned an R Squared value of .086 and an adjusted R Squared value of .07 . The Durbin-Watson statistic for the model was 2.216. The model was significant $(F=5.291 ; p<.0001)$. In the equation obtained for the final model, the gender term was significant: $2.854(.146) \operatorname{Gender}(\mathrm{female})(\mathrm{p}<.023)$ as was the variable used to capture use of the late night laboratories .928(.120)Use of 24 hour facility $(p<.069)$. In these terms the first number in each term represents the unstandardised coefficient. The value in brackets after this is the standardised coefficient. The name of the variable then follows. The $p$-value of the term is then shown in brackets).

According to this model, female gender and use of the 24 hour computer laboratories are positively associated with student marks. A new form of gender inequality seems evident; females perform better. Further research is recommended in order to understand the causal mechanisms that underlie this effect. What is notable is the absence of significance for any of the technological access variables. The Variance inflation factors for the model were taken to be acceptable; the highest was 1.094 and the lowest 1.001. Similarly, the tolerance values were also within a range of .914 for the lowest and .999 for the highest. Multicollinearity was therefore not taken to be a problem with the model. The probability-probability plot of the frequency of the standardised residuals reflected a normal distribution and the plot of the expected cumulative probabilities over the observed cumulative probabilities was not found deviate significantly from the normal diagonal plot of the regression standardised residuals. Values of the Standardised residuals, Studentised residuals, Mahalanobis distance, Cook's statistic and Leverage were saved in the analysis and inspected for outliers. With few outliers, the regression model was considered to be acceptable, with no major threats to its interpretability.

\subsection{Data}

Two models were first run for the 2011 data. The backward elimination model for the 2011 data was found to include the following significant variables: 1.061(.134)Use of the printers in the laboratory( $p<.01)-7.932(-.114)$ NSFAS loan $(p<.033)$ - 5.89(-.237)ParentsPay $(p<.0001)$. The model was significant $(p<.0001 ; F=9.474)$. It had a $R$ Squared value of .101 and an adjusted $R$ Squared value of .091, indicating that the variables in this model accounted for just less than ten percent of the variance in accounting marks. The Durbin-Watson statistic was 2.014 for this model. The results of the other tests of the assumptions of the model were taken to be acceptable. The variance inflation factors and tolerance values were taken to indicate that multicollinearity was not a problem for the model. According to this model, the more students used printers in the computer laboratories, the higher their accounting marks were. This variable might capture the extent to which students are engaged with the use of technology in their studies. However, it is not expected to be associated with resource scarcity because all students should have access to these printers, and because of cost reasons all students would be expected to use them. This variable might have picked up some aspect of work ethic. The dominant variable in this equation, with the highest standardised coefficient, is the parents pay variable. This association might capture the relatively large numbers of previously disadvantaged students that have entered the system (up by $15 \%$ from the previous year), that are not supported by bursaries or NSFAS loans. This equation is therefore considered to be dominated by the influence of resource constraints. The NSFAS loan variable is also taken to act as a proxy for resources constraints; these loans are granted to individuals that do not typically have the financial resources that studies require. Further research might indicate what the causal mechanisms are that underlie resource scarcity and its relationships with student academic performance.

\subsection{Data}

The model run for the 2012 data was found to have an R Squared value of .158 and an adjusted R Squared value of .143. The Durbin-Watson statistic for this model was 2.06. The model was significant ( $p<.0001 ; F=4.121)$. The following variables were found to be significant: - 1.241(-.110)Lack of Knowledge of Excel $(p<.031)+3.757(.176)$ Parents Pay $(p<.035)+5.072(.227)$ Bursary Pay $(p<.005)-3.999(.162)$ Own Computer $(p<.003)+3.252(.146)$ Windows $7(p<.006)$. 
However, the variance inflation values for the parents and the bursary items were higher than those of the other items (2.762 and 2.573, respectively). The tolerance values for these two items were also lower than those of the other variables in the equation (.362 and .389 respectively). The signs of the coefficients, however, were in the same direction. The equation was run again, twice, with one of these two variables included each time. When the bursary variable was excluded, the variables in the model loaded in with similar levels of significance, yet the parent payment variable was no longer significant in the model. When the parent payment variable was included but the bursary variable excluded the same variables were in the model, with similar significance levels, but the parent payment variable was in the model yet not at within the five percent level of significance $(p<.063)$. The variables in this model were taken to be significantly associated with student marks, except for the bursary and parents payment variables. The associations of the latter two variables are therefore not interpreted or discussed.

Whereas in 2010 none of the technological variables were found to be significantly associated with student marks, and two technological factors were found to be significant in the 2011 data, in 2012 three technological factors are found to be significantly associated with accounting marks. Students that have Windows 7 on their computers are found to have significantly higher levels of academic performance. Having the latest software on a student's computer might act as a proxy variable for being up to date with technological changes. According to Brown and Czerniewicz (2010), in the South African context one's economic life chances are significantly increased if one is on the side of a digital divide associated with technological literacy and being up to date with technology. This significant association supports this notion. However, the negative associations of the knowledge of Excel variable and the own computer variable are difficult to interpret. It may be possible that the influences of resources scarcities have already been picked up through the influence of the other variables and that there are other effects present that are unclear. It was considered possible that singularity or multicollinearity was present, and that the signs of these variables may have reacted to these, but the variance inflation factors and tolerance values were within reasonable ranges. Further research might shed light on these factors. For the purposes of further analysis, a factor analysis was performed across the three years in order to understand what changes in the underlying factor structure might have occurred.

\subsection{Factor Analysis Results 2010-2012}

Factor analyses were run for the years 2010, 2011 and 2012. The approximate Chi-Squared values for Bartlett's test of Sphericity were 427.94 (2010), 1033.7 (2011) and 789.4 (2012) with 78 degrees of freedom ( $p<.0001)$ for each of the years. The measures of sampling adequacy were taken to be acceptable for the models. The models were considered acceptable in terms of the interpretability of its results. According to the factor analysis of the 2010 data, knowledge of Excel, knowledge of Word, knowledge of Access and knowledge of Power-Point were found to load on factor one. This factor was interpreted as 'technological literacy'. Use of the printers in the computer laboratories and accounting marks were found to load on factor two. This factor was interpreted as 'academic performance', because it reflected the academic performance of students. Use of the twenty-four hour laboratory facilities and time spent in the average laboratory session were found to load on factor three. This factor was interpreted as 'technological facilities usage'. Waiting time for computers and rating of the computer laboratories were found to load on factor four. This factor was interpreted as 'technological facilities dissatisfaction'. Age and part-time work were found to load on factor five. This factor was interpreted as 'age cohorts', in that this might reflect the variance associated with relatively older students that were more likely to engage in part-time work to supplement their incomes while studying. The number of others that a student shares their computer with was found to load on factor six, together with the marks variable. This factor was interpreted as 'resource constraints', because this variable reflected the restrictions a student faces when needing to do academic work.

In the hope that the factor analyses might reflect changes that are occurring in the academic student context, the results of these factor analyses were compared and contrasted. Table 2 illustrates a summary of the changes in factor structure over the three years. The first two component categories seem to have been stable over time. Interestingly, although resource constraints are not found to load in the 2011 data, they are the factors associated with the least variance in the 2010 and 2012 data. Academic performance, however, is found to differ in its loadings over this period. Whereas academic performance was found to load on a factor that contributed the second highest level of variance in 2010 and 2011, in the latter year it was found to load together with technological facilities usage. In 2012 academic performance was found to load on the component category that contributed the second lowest variance, and to load together with age cohort effects. Having documented the changes in the factor structure associated with technological effects in this context, it is recommended that further research investigate these changes further, in order to unearth the causal mechanisms that underlie the changes over time in this context that relate to access to technological resources. 
Table 2. Summary of factor structure change over time

\begin{tabular}{|l|l|l|}
\hline Component Categories $\mathbf{2 0 1 0}$ & Component Categories 2011 & Component Categories $\mathbf{2 0 1 2}$ \\
\hline 1. Technological Literacy & 1. Technological Literacy & 1. Technological Literacy \\
\hline 2. Academic Performance & $\begin{array}{l}\text { 2. Technological facilities usage performance } \\
\text { effects }\end{array}$ & 2. Technological facilities usage \\
\hline 3. Technological Facilities Usage & 3. Technological Facilities Dissatisfaction & 3. Technological facilities dissatisfaction \\
\hline 4. Technological Facilities Dissatisfaction & 4. Age Cohorts & 4. Age cohorts performance effects \\
\hline 5. Age cohorts & & 5. Resources constraints \\
\hline 6. Resource Constraints & & \\
\hline
\end{tabular}

\section{Conclusions}

The research question addressed in this research was: What is the relationship between access to technology and accounting student performance?

It is concluded that the influence of technological facilities on student marks does not seem to be a dominant influence; they are dominated in the testing by associations relating to gender. It is concluded that the following may be trends. (i) In the most recent data, access to the latest software (Windows 7) was found to be significantly associated with higher student marks. This supports previous research that suggests that accessing the latest technology (Brown and Czerniewicz, 2010) is associated with being part of a digital elite that are on the one side of a 'digital divide' that directly contributes to an individual's success in knowledge tasks. Further research is recommended in order to follow these trends. It is acknowledged, however, that range restriction might be present; students selected into this university might already on the whole represent more advantaged individuals, considering that an outcome of this advantage is having an education that has allowed them to score highly enough to be accepted. Similar research is therefore suggested; particularly in contexts that are relatively more reflective of the country's resource constraints. (ii) Whereas gender was found to differentiate student marks (females had higher marks) in 2010, the more recent contexts seem to indicate that gender marks are gender-neutral. This is also taken to be encouraging, because a reverse-gender bias is surely not a sustainable outcome in this context. Recommendations are considered as follows.

\section{Recommendations for Practice}

On the basis of the conclusions, the following recommendations are made. Firstly, it is recommended that all students in this class be provided with their own computer, with (at the very least) Windows 7 or the latest software installed. The positive association between Windows 7 on a student's own computer and student marks in the latest data is taken to represent the influence of both of these factors. If a digital divide is developing in this society, then it might be the responsibility of a university to ensure that it bridges this divide for all its students. Secondly, it is recommended that all dimensions of resource scarcity be proactively addressed; if time spent in the 24-hour computer laboratories differentiates the experience of university studies, then further research is recommended into how these technological differences in the experience of studying accounting can be addressed. Greater interaction and socialisation between students may need to be encouraged in order to ensure that the common languages of technology transmit amongst all students. It is also recommended that the education system prioritises skills and knowledge and the transmission of these skills and knowledge over all other objectives.

\section{References}

Brown, C., \& Czerniewicz, L. (2010). Debunking the 'digital native': beyond digital apartheid, towards digital democracy. Journal of Computer Assisted Learning 26:357-369.

Bryant, S.M., \& Hunton J.E. (2000). The Use of Technology in the Delivery of Instruction: Implications for Accounting Educators and Education Researchers. Issues in Accounting Education 15(1):129-162.

Callaghan, C.W. (2014a). R\&D Failure and Second Generation R\&D: New Potentialities. Mediterranean Journal of Social Sciences, 5(3), $11-24$.

Callaghan, C.W. (2014b). Values and Research Productivity. Mediterranean Journal of Social Sciences, 5(1), 453-465.

Coldwell, D.A.L., \& Callaghan, C.W. (2013). An empirical analysis of career subject major choices on the basis of internal versus external factors. South African Journal of Economic and Management Sciences, 16(3), 244-257.

Cradler, J., McNabb. M., Freeman, M. \& Burchett, R. (2002). How Does Technology Influence Student Learning. Learning \& Leading 
with Technology 22(8):72-80.

Dunkle, K.L., Jewkes, R.K., Brown, H.C., Yoshihama, M., Gray, G.E., Mclntyre J.A. \& Harlow, S.D. (2004). Prevalence and Patterns of Gender-based Violence and Revictimisation among Women Attending Antenatal Clinics in Soweto, South Africa. American Journal of Epidemiology 160(3):230-239.

Field, A. (2009). Discovering Statistics using SPSS (3rd Edition). London: Sage.

Ginwright, S., \& Cammarota, J. (2002). New Terrain in Youth Development: The Promise of a Social Justice Approach. Social Justice 29(4):82-95.

Habib, A. \& Bentley, K. (2008). Racial Redress and Citizenship in South Africa. Cape Town: Human Sciences Research Centre Press.

Isaacs, E., Visser, K., Friedrich, C. \& Brijlal, P. (2007). Entrepreneurship education and training at the Further Education and Training level in South Africa. South African Journal of Education 27(4):613-629.

Morrison, A.M., White R.P., Van Velsor, E., \& The Centre for Creative Leadership. (1987). Breaking the glass ceiling: can women reach the top of America's largest corporations? Reading, MA: Addison-Wesley.

Munusamy, R. (2012). Marikana, Malema, Rebellion, Revolution. Daily Maverick, available at:

http://www.dailymaverick.co.za/article/2012-09-12-marikana-malema-rebellion-revolution (Accessed 10 June 2013).

Nanackchand. V., \& Berman, K. (2012). Visual graphics for human rights, social justice, democracy and the public good. South African Journal of Education 32(4):465-478.

O'Connor, J., \& Geiger, M. (2009). Challenges facing primary school educators of English Second (or Other) Language learners in the Western Cape. South African Journal of Education 29:253-269.

Olele, C., \& Uche C. (2012). Popular misconceptions of entrepreneurship education in a higher education institution in Nigeria. South African Journal of Higher Education 26(6):1200-1215.

Özler B. (2007). Not Separate, Not Equal: Poverty and Inequality in Post-apartheid South Africa. Economic Development \& Cultural Change 55(3):487-529.

Phillipson, R. (1996). Linguistic imperialism: African perspectives. ELT Journal 50(2):160-167.

Powell, G.N., Butterfield, D.N. \& Parent, J.D. 2002. Gender and Managerial Stereotypes: Have the Times Changed? Journal of Management 28(2):177-193.

Prensky, M. (2001). Digital Natives, Digital immigrants. On the Horizon 9(5). Available at: http://www.marcprensky.com/writing/ Prensky\%20-\%20Digital\%20Natives,\%20Digital\%20Immigrants\%20-\%20Part1.pdf (Accessed 5 June 2013)

Ridgeway, C.L. \& Correl, S.J. (2004). Unpacking the Gender System. A theoretical perspective on gender beliefs and social relations. Gender \& Society 18(4):510-531.

The World Bank. (2012). GINI index. Available at: http://data.worldbank.org/indicator/SI.POV.GINI. [Accessed 22 January 2012]

Thinyane. H. (2010). Are digital natives a world-wide phenomenon? An investigation into South African first year students' use and experience with technology. Computers \& Education 55:406-414.

Urban, B., Van Vuuren, J., \& Barreira, J. D. (2008). High-Growth Entrepreneurs: The Relevance of Business Knowledge and Work Experience on Venture Success. Journal of Contemporary Management 5:58-71.

Van Wyk, B. \& Jacobs, A.H.M. (2012). Cultural change and the emergence of the knowledge-driven economy. South African Journal of Higher Education 26(6):1170-1181.

World Economic Forum. (2012). The Global Competitiveness Report. Available at: http://www3.weforum.org/docs/WEF_Global CompetitivenessReport_2012-13.pdf (Accessed 30 January 2013).

Xaba, M.I. (2012). A qualitative analysis of facilities maintenance- a school governance function in South Africa. South African Journal of Education 32(2):215-226.

Xie, Y., \& Shauman, K.A. (2003). Women in Science: Career Processes and Outcomes. Boston, MA: Harvard University Press. 